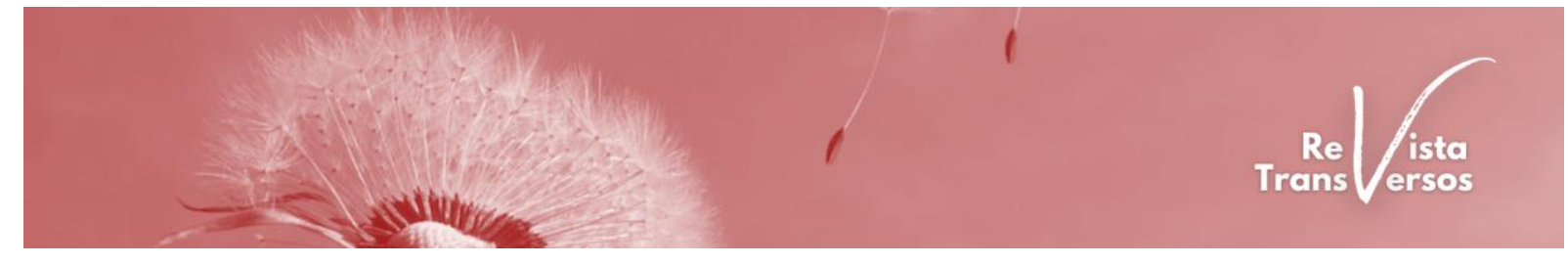

DOI: $10.12957 /$ transversos.2021.62326

\title{
ENSINO DE HISTÓRIA NA EDUCAÇÃO BÁSICA: A EXPERIÊNCIA HISTÓRICA ROMANA, E O TEMPO PRESENTE, NA SALA DE AULA ${ }^{1}$
}

\section{HISTORY TEACHING IN BASIC EDUCATION: THE HISTORICAL ROMAN EXPERIENCE, AND THE PRESENT TIME, IN THE CLASSROOM}

\author{
Naicon de Souza Brinco \\ Prefeitura Municipal de Macaé \\ naiconro@hotmail.com
}

\section{Resumo:}

O presente artigo investiga a hipótese de que o ensino de História pode ocorrer a partir da historicização do tempo presente e mobilização de conceitos históricos na incorporação da experiência histórica ao espaço de experiência dos estudantes. Operamos com prática metodológica mediada pela narrativa fundamentada na ação dos personagens -, e pela mobilização de conceitos históricos - na percepção crítica do mundo. Tais reflexões são resultado da pesquisa de mestrado que realizamos no âmbito do ProfHistória/UERJ, no ano de 2020, em duas classes do sexto ano da educação básica. Os resultados apresentam o protagonismo dos discentes ao mobilizarem o conhecimento histórico e habilidades históricas na elaboração cooperativa de cinco narrativas audiovisuais, no game Gacha Life.

Palavra-Chaves: Ensino de História; Keywords: History Teaching; Learning in Aprendizagem em História; Narrativa; Roma

\begin{abstract}
This article investigates the hypothesis that the teaching of history can occur from the historicization of the present time and the mobilization of historical concepts in the incorporation of historical experience into the students' space of experience. We operate with a methodological practice mediated by narrative - based on the action of the characters - and by the mobilization of historical concepts - in the critical perception of the world. Such reflections are the result of the master's research that we carried out within the scope of ProfHistória/UERJ in 2020, in two classes of the sixth grade of basic education. The results show the role of students in mobilizing historical knowledge and historical skills in the cooperative elaboration of five audiovisual narratives, in the game Gacha Life.
\end{abstract}

History; Narrative; Rome.

\footnotetext{
${ }^{1} \mathrm{O}$ presente artigo é parte de uma investigação que ocorreu no âmbito da dissertação de mestrado intitulada Ensino de História na cibercultura: narrativas sobre a ocupação do território e cidadania a partir da experiência histórica romana e o tempo presente sob a supervisão da Profa. Dra. Maria Aparecida da Silva Cabral, no Mestrado Profissional em Ensino de História na Universidade do Estado do Rio de Janeiro - Profhistória/UERJ.
} 


\section{Introdução}

Por que ensinar História na educação básica? Por vezes, na experiência em sala de aula, nós professores somos questionados pelos discentes sobre o motivo de estudarem História. Essa questão tem raízes profundas na historicidade da disciplina, nos diferentes objetivos que assumiu no decorrer do século XIX e XX (BITTENCOURT, 2007). Porém, consideramos que anterior a uma resposta aos alunos, o professor deve ter bem fundamentado suas próprias motivações. Pois, se não há segurança acerca dos objetivos de nossa prática enquanto professores, como pode-se esperar que o aprendiz perceba sentido naquilo que está sendo proposto que aprenda?

A reflexão sobre a prática de atuação nas salas de aula pode contribuir nesta relevante questão, ao auxiliar os professores a posicionar sua forma de atuar sobre a realidade e perceberse como autores das aulas que constroem junto aos estudantes (MATTOS, 2006), distanciandose do agir como ferramentas de uma escola mecanicista ou forças da natureza movidas pela vocação (RICOEUR, 2011). Pois, a todo momento são realizadas escolhas discursivas no decorrer das aulas de História (ALBUQUERQUE JR, 2016).

Paulo Freire (1987) nos ensina que uma prática educacional, que promove a liberdade, dialoga com o universo temático dos discentes. Nesta perspectiva a aula é anterior a si mesma, ocorrendo inicialmente como um futuro possível idealizado no horizonte de expectativas (KOSELLECK, 2006) do professor, em estratos de possibilidades a serem percorridas. Sendo relevante a participação dos estudantes com os saberes e conhecimentos acerca do passado que possuem, fruto de suas trajetórias (FERREIRA, 2018).

A questão cultural está no "chão da escola" e potencializa a aprendizagem ao valorizar e reconhecer cada sujeito envolvido e ao combater "todas as formas de silenciamento, invisibilização e/ou subalternização de determinados sujeitos socioculturais" (CANDAU, 2009: p.43).

A hipótese de trabalho a qual atuamos é a de que o ensino de História pode ocorrer a partir da historicização do tempo presente (PEREIRA; SEFFNER, 2008) e mobilização de conceitos históricos (FERREIRA, 2018) na incorporação da experiência histórica - do passado ao espaço de experiência dos estudantes (KOSELLECK, 2006).

Este posicionamento implica na defesa da autonomia do professor de História em sua prática pedagógica e na promoção dos estudantes pensarem a si mesmos e ao mundo de forma 
problematizadora, sem separar o conhecimento histórico escolar das suas ações nos contextos em que vivem (FREIRE, 1987).

O professor, nesta perspectiva de autonomia, planeja a aula traçando uma rota por caminhos cheios de imprevistos e intempéries, pois assim como "não se entra duas vezes no mesmo rio" ${ }^{2}$, não se adentra duas vezes na mesma classe. No desenvolvimento das aulas, novas possibilidades didáticas podem surgir, questões logísticas e estruturais das unidades escolares podem forçar a modificação ou paralisação de atividades planejadas. Conhecer e refletir acerca das próprias escolhas teóricas e metodológicas, pode ser de auxílio ao professor (SEFFNER, 2018) na construção e desenvolvimento das aulas.

Ao construir e desenvolver tal planejamento, onde o professor poderia encontrar uma segura representância da realidade, enquanto expectativa de aula, que ao se realizar pode apresentar diferentes cenários? Poder-se-ia buscá-la na academia ou em cartilhas e planos de aula, prontos para serem aplicados? Ou nos currículos, em seus conteúdos, competências e habilidades? O saber da experiência possibilita, sozinho, dar conta de uma prática de ensino libertadora? Legitimarmos tradições e crenças, como conhecimento histórico com pretensão à verdade, promove uma prática que incentiva a autonomia dos discentes?

Consideramos que o planejamento, a escolha de fontes, a construção metodológica e a atuação em sala de aula são orientadas por um conjunto de contribuições postas em diálogo, organizadas pelo professor de História. Abrangem a historiografia e as reflexões teóricas produzidas na academia, os saberes docentes (TARDIF, 2012), a logística do espaço escolar em seus limites e possibilidades, e o universo temático mínimo dos estudantes - que se encontra nas relações e vivências dos discentes com o mundo (FREIRE, 1987).

Segundo Freire (1987), investigar um tema gerador é investigar o atuar dos alunos sobre a realidade, abordando fatos concretos junto com os estudantes, que são sujeitos da investigação. Promovendo que os discentes realizem, de forma consciente, a historicização dos fenômenos do tempo presente, de seus espaços sociais, compreendendo-se como agentes históricos (PEREIRA; SEFFNER, 2008). Sob tais considerações buscamos, na investigação realizada, um tema gerador para construção do plano de ensino do conteúdo curricular a ser abordado, em um movimento de ida e volta entre o abstrato e o concreto, que objetiva o desenvolvimento da percepção crítica

\footnotetext{
${ }^{2}$ Expressão do filósofo pré-socrático Heráclito, segundo o qual apesar da ilusão de estabilidade, de cada percepção, não há nada fixo, sendo a realidade sempre conjuntural e conflitante (BOCAYUVA, 2010: p. 410)
} 
da realidade (FREIRE, 1987: p. 92).

A investigação em tela ocupa-se com o ensino do conteúdo curricular da educação básica "Roma - Instituições e Participação Política" (MACAÉ, 2012) com o recorte temporal do segundo século a.C., sob o tema das disputas de ocupação do território. Sua correlação às lutas sociais no direito à terra e à cidadania. Sendo realizada no Colégio Municipal Elza Ibrahim, em turmas de sexto ano do Ensino Fundamental, na cidade de Macaé, no estado Rio de Janeiro.

O tema gerador no tempo presente, em diálogo com o currículo da Rede Municipal de Macaé, para o ensino da experiência histórica romana, foi referenciado nas disputas de ocupação do território na década 1980 no Brasil e na década de 2010 em Macaé - a partir de movimentos sociais camponeses.

O movimento social Movimento dos Trabalhadores Rurais Sem Terra (MST) é parte das aulas integrantes deste estudo pela sua atuação na cidade de Macaé e sua relação com discentes da unidade escolar e com o governo municipal, no fornecimento de produtos alimentícios. Desta maneira, o assentamento Projeto de Desenvolvimento Sustentável (PDS) Osvaldo de Oliveira e o Acampamento Edson Nogueira, foram espaços selecionados para integrar as aulas por se relacionarem diretamente à cultura escolar do colégio locus da pesquisa. A dinâmica ocorre, pois (i) parte da alimentação ofertada pelo colégio aos estudantes é proveniente da produção agroecológica destes espaços; (ii) pela presença de discentes matriculados que participam ou já participaram deste assentamento/acampamento; e (iii) a dinâmica de mobilidade domiciliar das famílias atendidas na unidade escolar e os lugares no qual estão localizados o Acampamento Edson Nogueira e o Assentamento Osvaldo de Oliveira. ${ }^{3}$ Estes espaços foram localizados e visitados virtualmente pelo Google Earth ${ }^{4}$

A pesquisa em tela possuiu o objetivo geral de operar, na sala de aula, o ensino de História com o suporte metodológico da narrativa, a partir de eventos geradores no tempo presente em diálogo às vivências dos estudantes. Como objetivos específicos, operar em sala de aula a mobilização de conceitos históricos, historicização do tempo presente, apropriação do conteúdo curricular e identificação de continuidades históricas.

\footnotetext{
${ }^{3}$ Com a parceria entre a Prefeitura Municipal de Macaé e a Cooperativa Agropecuária dos Pequenos Produtores e Trabalhadores Rurais do Assentamento Celso Daniel por meio da COOPMAC - alimentos produzidos no Acampamento Edson Nogueira e no Assentamento Osvaldo de Oliveira chegam à escola Municipal Elza Ibrahim, compõem a merenda escolar e são consumidos pelos estudantes.

${ }^{4}$ Disponível em: <https://www.google.com.br/intl/pt-BR/earth>. Acessado em: 30 mar. 2020.
} 
Portanto, abordamos o conteúdo curricular em sua relação com o mundo e as vivências dos estudantes (VIGOTSKI, 2008). Na busca de aproximarmos nosso pensar de nosso agir, na construção de um conhecimento histórico escolar que é práxis (FREIRE, 1987), almejamos contribuir nos debates acerca do Ensino de História na educação básica ao mobilizar no tempo presente narrativas não hegemônicas de grupos historicamente subalternizados - por vezes silenciados (KALLÁS, 2017), operar com a narração da fábulas ao mobilizar conceitos e com o processo de construção de narrativas audiovisuais em mídias digitais, em diálogo com a cibercultura $^{5}$, no aplicativo sugerido pelos estudantes, o Gacha Life.

\section{A narrativa histórica e a ficcional em sala de aula: entrecruzamentos digitais.}

Operamos com a teoria da narratividade proposta por Ricoeur (2010a; 2010b) em diálogo com a noção de experiência e narrativa de Benjamin (2012a); a ferramenta heurística de espaço de experiência e horizonte de expectativas de Koselleck (2006); e a hipótese de regimes de historicidade de Hartog (2013). Na incorporação do passado enquanto conteúdo curricular, de forma a qual o presente não seja hipertrofiado a ocupar todo o espaço de experiência e avançar sobre horizonte de expectativas (KOSELLECK, 2006; HARTOG, 2013), silenciando narrativas e experiências passadas (BENJAMIN, 2012b)

O conceito de narrativa, na perspectiva de Ricoeur (RICOEUR, 2010a), é caracterizado pelo agenciamento de fatos, que ao serem dispostos em um sistema, pela composição da intriga, tem a potência de explicar algo que aconteceu em um singular coletivo. Operar com tal conceito na sala de aula, potencializado com suporte da imaginação, nos auxiliou a dialogar com as formas dos estudantes se posicionarem no mundo, em meio ao contexto social a qual vivem (FERNANDES, 2019). Em um entrecruzamento da narrativa histórica e das atividades, no qual os alunos produzam narrativas ficcionais no campo do possível (RICOEUR, 2010b). Adentrando no fértil terreno da imaginação, de jovens que estão iniciando a adolescência, ao narrar histórias - uma ferramenta de acumulação e transmissão da experiência tão antiga que se confunde com o início da história humana (FERNANDES, 2019).

A construção narrativa pela composição da intriga, para Ricoeur (2010b), é uma produção ativa, que mantém os caracteres como singulares, e na representação da ação dos

\footnotetext{
${ }^{5}$ Operamos com a perspectiva de que o conceito de cibercultura representa "a cultura contemporânea mediada pelas tecnologias digitais" (SANTOS; WEBER, 2014: p. 13).
} 
personagens tem a potência de universalizar a narrativa enquanto singular coletivo. Em histórias narradas que a humanidade conta a si mesma e que abrangem não só o passado como também o presente e, para os jovens nascidos em meio a expansão das mídias digitais, parecem ter maior autenticidade quando contadas de forma visual (FERNANDES, 2019).

A contribuição de Ricoeur fundamenta, neste estudo, as operações do ensino pela narrativa de fábulas e de personagens históricos, a operação de deslocamento no tempo em diferentes processos históricos, além de atividades de entrecruzamento entre História e ficção (RICOEUR, 2010a; 2010b).

Ao fazer uso das mídias digitais, em diálogo com a cibercultura, no espaço de incerteza das transformações tecnológicas, foi possível movimentar-nos entre recursos pedagógicos analógicos, como livros, cartolinas e jornais impressos, e digitais, como celulares e recursos do ciberespaço (LUCCHESI; MAYNARD, 2019). Sendo possível encurtar distâncias geográficas na exploração de locais, que por motivos logísticos, de outra forma os estudantes não teriam acesso com a mediação do professor (BRINCO; CABRAL, 2020).

Ao aceitar o desafio de aprender junto com os alunos a utilizar o game Gacha Life, nos propusemos a experimentar e brincar (LUCCHESI; MAYNARD, 2019) em diálogo aos referenciais da narrativa e das vivências dos estudantes.

O desenvolvimento de atividades com a contação e construção de narrativas - uma prática tão antiga quanto a nossa história, enquanto humanos - pode de forma híbrida ser operada junto ao uso de mídias digitais - seja em jogos, vídeos, construção de avatares ou animações - com uso da imaginação (CUESTA, 2015). Nesse fazer, a aprendizagem ocorre no espaço da brincadeira, com a possibilidade de selecionar, junto com os alunos, aplicativos em que não há uma busca por vencer e sim cooperar com o outro, na qual a principal motivação seja a de participar e, em sua dinâmica, desenvolva ações a partir do que consideram a vida real, referenciada nas suas vivências e no conteúdo de História (VYGOTSKY, 2008). A produção narrativa insere o discurso dos alunos no espaço e no tempo, além de possuir importante papel na significação do tempo histórico (SANTOS, 2015). Portanto, a aprendizagem em História que seja significativa para o estudante transcende ao conteúdo curricular, sem abrir mão dele, pois dialoga com as experiências e as práticas culturais dos discentes. (BRINCO; CABRAL, 2020: p.73)

As mídias digitais, nesta perspectiva, foram operadas como uma mediadora entre a cultura escrita e a visual na construção de narrativas (FERNANDES, 2019) na prática de ensino em História.

\section{Local da pesquisa}

A escola locus da presente pesquisa, é localizada na cidade de Macaé (Figura 1), cerca de 
180 km da capital do Estado do Rio de Janeiro (MACAÉ, 2014). Possui população estimada, em 2019, de 256.672 pessoas (BRASIL, 2010a) e uma área total de $1.216 \mathrm{~km}^{2}$ (BRASIL, 2020a).

Figura 1 - Cidade de Macaé, Rio de Janeiro, Brasil.

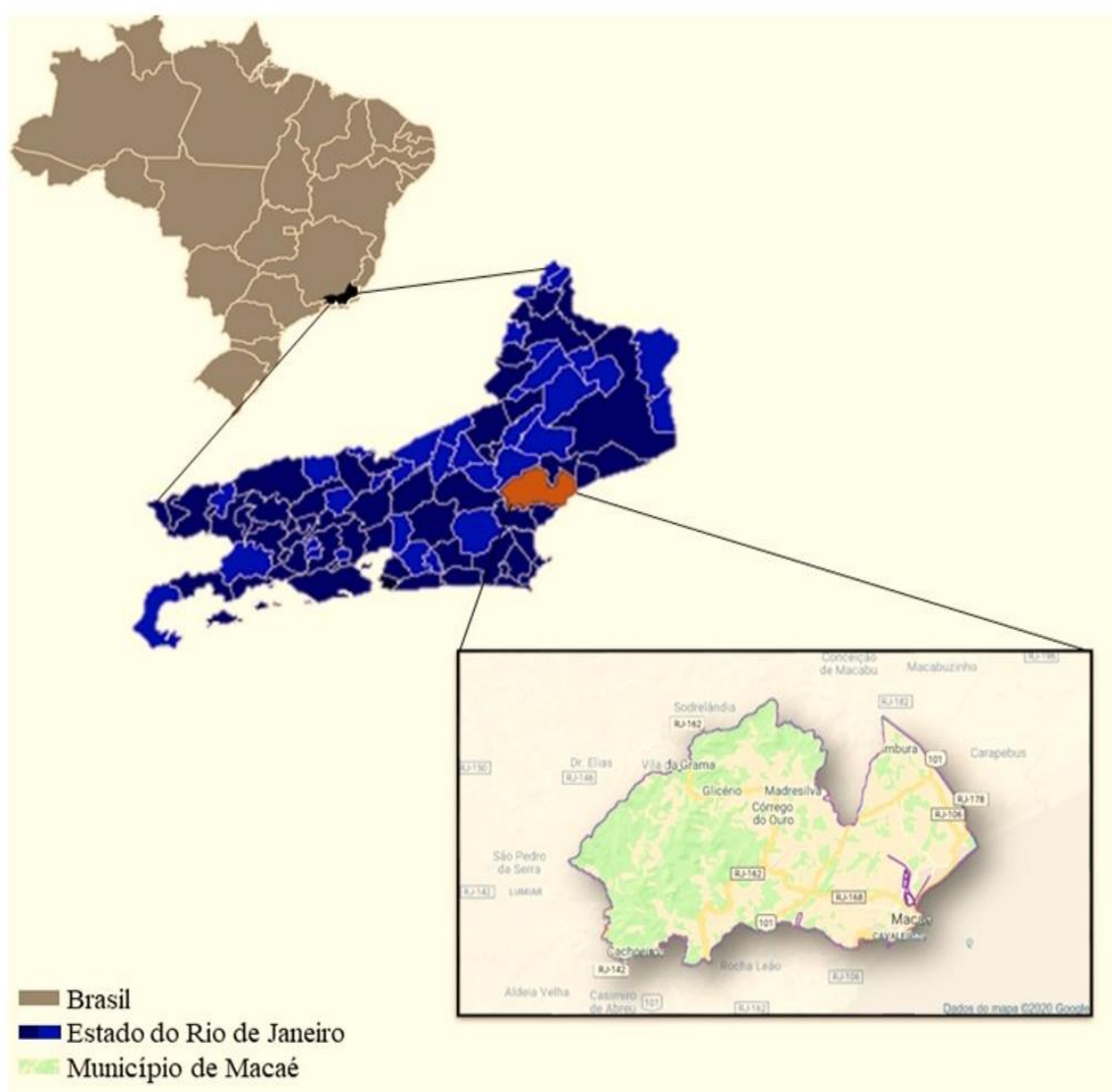

Fonte: Elaborado pelo autor, 2020

Conhecida como Capital Nacional do Petróleo, em seu território estão as instalações da Petrobrás que operam em toda Bacia de Campos. Em 2017, apresentou o Produto Interno Bruto (PIB) per capita de R\$ 62.961,48 e a maior média salarial do país - 6,7 salários mínimos (Tabela 1) (BRASIL, 2020b).

Tabela 1 - Panorama Econômico de Macaé

PANORAMA ECONÔMICO DE MACAÉ

$\begin{array}{ll}\text { PIB per capita } & \mathrm{R} \$ 62.961,48 \\ \text { Média salarial } & 6,7 \text { salários mínimos } \\ \text { Renda per capita menor que } 1 / 2 \text { salário mínimo } & 31,5 \%\end{array}$

Fonte: $\mathrm{O}$ autor, 2020 
Segundo o Censo Rural do IBGE (BRASIL, 2019a), realizado em 2017, há na cidade 886 estabelecimentos agropecuários que ocupam uma área total de 71.198 hectares, representando $58,55 \%$ do território total da cidade - na qual há 2.470 pessoas ocupadas (Tabela 2). Destas, $71,53 \%(1.767 / 2.470)$ possuem laços de parentesco com o produtor. Outros $17,93 \%$ (443/2.470) são trabalhadores permanentes, 9,20\% (227/2.470) são trabalhadores temporários e $1,34 \%(33 / 2.470)$ parceiros se ocupam da atividade agropastoril sem parentesco com os produtores. Indicativo que a maior parte dos estabelecimentos integra a agropecuária familiar, visto que o número de máquinas se resume a 197 tratores e 86 semeadeiras, o que não representa uma média de uma máquina para cada duas unidades agropecuárias.

Tabela 2 - Estabelecimentos agropecuários

\begin{tabular}{ll}
\hline & ESTABELECIMENTOS AGROPECUÁRIOS \\
\hline Total & 886 \\
Área total & $71.198 \mathrm{ha}(58.55 \%$ do território total da cidade $)$ \\
Pessoas ocupadas & 2.477 (71\% com laço de parentesco com o produtor) \\
\hline
\end{tabular}

Fonte: $\mathrm{O}$ autor, 2020.

O município de Macaé regionalizou a cidade em setores administrativos, nomeando-os por cores, de acordo com características socioeconômicas. O colégio, locus da investigação em tela, recebe alunos do setor administrativo Vinho, que engloba cinco bairros - total da população estimada em 2019 de 59.362 pessoas, concentrando grande parcela da força de trabalho da cidade. No entanto, a média salarial é expressivamente abaixo da apresentada pelo município, com $28,91 \%$ dos domicílios possuindo uma renda per capita inferior a meio salário mínimo, não ultrapassando o valor de um salário mínimo em mais da metade dos domicílios (MACAÉ, 2014).

Em meio aos contrastes socioeconômicos apresentados, a unidade escolar, inaugurada em 2006, atendeu em 2019, em três turnos, 31 turmas de Fundamental II e 6 turmas de Fundamental I, incluindo 5 classes de correção de fluxo e 6 turmas de EJA (Educação de Jovens e Adultos).

Apesar de problemas estruturais, como falta de manutenção e de água, apresenta uma extensa produção de atividades e projetos interdisciplinares - ofertados a seus 1.001 alunos matriculados (BRASIL, 2019b) - de iniciativa do corpo docente e da equipe diretiva: oficinas de 
teatro, circuitos matemáticos, exposições artísticas, eventos culturais, feiras literárias e de cinema.

\section{Os alunos participantes da pesquisa}

No decorrer dos oito anos de atuação como professor no Colégio Municipal Elza Ibrahim, percebemos que os alunos demonstravam uma certa vivência em relação às práticas agrícolas. No sexto ano do ensino fundamental, ao abordar o conteúdo curricular "Revolução Neolítica e Egito" (MACAÉ, 2012), durante os diálogos sobre agropecuária, sedentarismo, ciclo de vazantes do rio Nilo, fertilidade do solo e tecnologias de irrigação, observamos uma constante interação dos estudantes. Participavam com saberes referenciados em suas vivências.

Este fenômeno fez surgir indagações sobre os modos de vida e as relações dos discentes e de suas famílias com o campo.

A partir destes questionamentos e do diálogo com os alunos, foi identificado no colégio discentes que participavam, junto a suas famílias, do assentamento PDS (Projeto de Desenvolvimento Sustentável) Osvaldo de Oliveira, vinculado ao MST (Movimento dos Trabalhadores Rurais Sem Terra). Ademais, a ocorrência percebida da mobilidade domiciliar entre o setor urbano e rural de Macaé apresenta o fenômeno dos sujeitos levarem consigo para áreas mais urbanas - em assentamentos precários e por vezes considerados irregulares, próximos geograficamente da unidade escolar - práticas como a criação de galinhas, pequenas hortas no quintal, na qual a conquista da terra pode vir a significar a independência e a construção da noção de comunidade (LEAL; COSTA, 2012).

Duas classes de sexto ano da educação básica participaram da pesquisa em tela: F6203 e F6204.

A F6203 (Gráfico 1) teve o total de 42 estudantes durante o ano letivo, no entanto, concluíram 35 alunos, com idade entre 11 e 13 anos. Quatorze meninas e vinte e um meninos; vinte e nove negros e seis brancos. Três alunos PCDs: um cadeirante, um aluno e uma estudante com deficiência intelectual, que foram acompanhados por uma profissional auxiliar escolar. Percebemos ser esta uma das classes com maior número de ocorrências por questões disciplinares entre as 7 turmas de sexto ano.

Passaram pela F6204 (Gráfico 2) um total de 39, finalizando o ano letivo 35 estudantes. A classe é formada por vinte meninos e quinze meninas, vinte e quatro estudantes negros e onze brancos. Há um discente PCD, com deficiência intelectual, um com TDAH e um com altas habilidades. Percebemos ser considerada "mediana" nos conselhos de classe, com baixo número 
de ocorrências disciplinares.

Gráfico 1 - Distribuição da F6203 por gênero e por características étnico raciais.

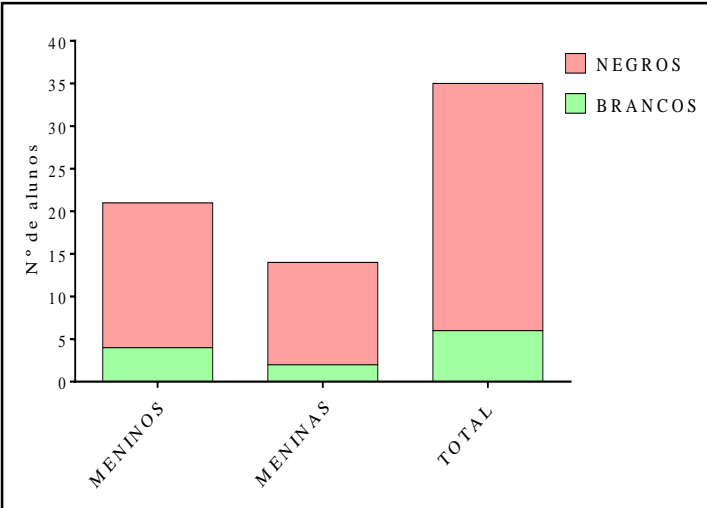

Gráfico 2 - Distribuição da F6204 por gênero e por características étnico raciais

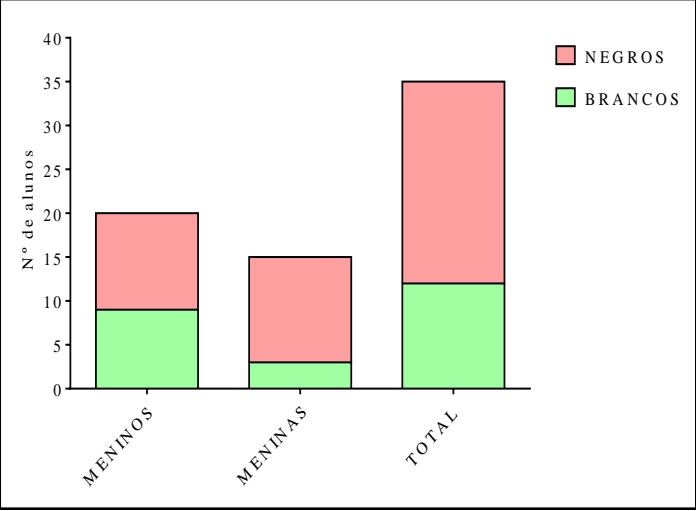

Fonte: $\mathrm{O}$ autor, 2020.

\section{Fontes}

A seleção dos fenômenos e das fontes, operadas em sala de aula com os alunos, é realizada a partir de experiências e percepções do pesquisador, geradores de indagações que à luz da teoria e do método de pesquisa, tencionam refletir sobre possibilidades para prática do ensino de História. Os processos de disputa do território no tempo presente, escolhidos para análise de fontes em sala de aula, têm como referencial a fala camponesa - dos sujeitos que participam do fenômeno.

As fontes, em sala de aula, foram operadas nos formatos: (i) impresso: em xerox fornecida pela escola e o livro didático; e (ii) digital: nos celulares dos discentes e do professor, notebook pessoal do professor, Datashow e caixa de som fornecidos pela escola.

$\mathrm{Na}$ construção de uma linha do tempo com o tema das disputas pelo território, os estudantes utilizaram fontes previamente selecionadas pelo professor, além das incluídas por sugestões dos alunos.

Acerca de Roma no século II a.C., os alunos utilizaram o livro didático "Vontade De Saber História” (PELLEGRINI, DIAS, GRINBERG, 2015) páginas 223 a 242, que trata da crise do império romano no século II a.C.. Além do texto "O problema dos sem-terra não é de hoje: a reforma agrária na Roma Antiga" do blog de divulgação científica "Para Entender História" do Prof. Dr. Fábio Pestana (RAMOS, 2010).

Ao tratar a formação do MST, nas décadas de 1980 e 1990, os estudantes operaram com o site "Memorial da Democracia" (MEMORIAL DA DEMOCRACIA - MST REALIZA 
PRIMEIRO CONGRESSO NACIONAL, [S.d.]), que noticia o primeiro congresso nacional do Movimento dos Trabalhadores Rurais Sem Terra e o site do MST que apresenta uma linha do tempo sobre acontecimentos relevantes para a formação do movimento social (O MST: NOSSA HISTÓRIA, [S.d.])

Sobre as disputas na ocupação do território em Macaé os discentes operaram com as notícias publicadas pelo Coletivo de Comunicação do MST RJ "Sob ameaça de despejo, famílias assentadas em Macaé (RJ) resistem e inauguram casa de farinha" (ALCÂNTARA, 2019), "Mais de 60 famílias assentadas estão sob ameaça de despejo em Macaé (RJ)” (PITASSE, 2019) e o vídeo “Unidade Pedagógica de Agroecologia Acampamento Edson Nogueira (RJ)” dirigido pela Brigada Audiovisual Eduardo Coutinho (BRIGADA AUDIOVISUAL EDUARDO COUTINHO (MST), 2019) .

Analisaram ainda o artigo "Implantação de Escola Agroecológica na Serra recebe apoio na Câmara” publicado no jornal da cidade O Debate On (REDAÇÃO, 2018) e por iniciativa dos estudantes adicionamos às fontes o artigo "A luta de trabalhadores rurais sem terra pelo assentamento Osvaldo de Oliveira” do Mapa de Conflitos Envolvendo Injustiça Ambiental e Saúde no Brasil publicado pela FIOCRUZ (FIOCRUZ E FASE, [S.d.]).

Foram apresentadas no Datashow a tirinha "Turminha do MPF" (BRASIL, MINISTÉRIO PÚBLICO FEDERAL, [s. d.]) , publicada pelo Ministério Público Federal, que aborda de maneira didática o conceito de Reforma Agrária. E os vídeos curtas-metragens "Vida Maria" (RAMOS, 2006) e "Sem Terrinha em Movimento" da Brigada Audiovisual do MST (BRIGADA DE AUDIOVISUAL DO MST, 2009).

Foram consultadas, como referência para abordagem em sala de aula do PDS Osvaldo de Oliveira, a pesquisa de dissertação de mestrado do Programa de Pós-Graduação em Serviço Social e Desenvolvimento Regional da Escola de Serviço Social da UFF de Niterói intitulada O Projeto De Desenvolvimento Sustentável (PDS) e a Construção de Novos Modelos de Assentamento Rural: O Caso do Assentamento Osvaldo de Oliveira do MST em Macaé-RJ (OLIVEIRA, 2018), o artigo Que a Universidade se Pinte de Povo (MONTEIRO, 2017) e o Diário Oficial [da] República Federativa do Brasil (BRASIL, 2010b).

Foram consultadas como referência para abordagem em sala de aula do acampamento Edson Nogueira artigos da Prefeitura Municipal de Macaé (MONTEIRO, 2013), da Câmara Municipal de Macaé (BENITES, 2018), do Jornal Prensa de Babel (VARGAS, 2018), do jornal 
Brasil de Fato (CASTRO, 2019; MESQUITA, 2019) e do Movimento dos Trabalhadores Rurais Sem Terra (VERGARA, 2019).

\section{Do método e da prática}

Consideramos a aula um processo dinâmico, criação individual e coletiva sempre em movimento, que em uma ponta encontra o texto historiográfico e na outra a sala de aula - na qual se destaca o aluno (MATTOS, 2006). Ao atuarmos nesta perspectiva, o diálogo entre o professor e os estudantes na apresentação dos critérios de estruturação e avaliação das atividades (SEFFNER, 2018) teve a potência de promover a abertura de possibilidades metodológicas.

A escrita do planejamento, as escolhas de fontes e do método a serem utilizados, foram orientadas pelas reflexões teóricas e por nossas representações da prática de ensino, após oito anos atuando no sexto ano do Ensino Fundamental na unidade escolar locus da presente pesquisa. Adaptações de cronograma e dificuldades ocasionadas por questões estruturais e logísticas, no desenvolvimento do planejamento, puderam ser previstas e contornadas com base no conhecimento acumulado com a experiência de atuação em anos anteriores.

No primeiro momento, foram coletados dados sobre uso das mídias digitais, acesso à internet e redes sociais pelos estudantes. Realizadas duas rodas de conversa e uma produção textual, nas quais os alunos relataram seus usos acerca do ciberespaço. Esta etapa da pesquisa foi relevante para conhecer as possibilidades e caminhos que poderiam ser percorridos no processo de ensino.

Ao conversar com os alunos sobre a proposta de trabalho, foi apresentada a atividade de construção de vídeos no qual os discentes encenariam de forma teatral narrativas por eles escritas, com uso da imaginação, que dialogasse com as experiências históricas estudadas. Duas estudantes sugeriram o uso do aplicativo Gacha Life para construção de avatares e vídeo animações. O aplicativo permite que o usuário construa avatares customizados que interagem entre si em

diversos cenários. É possível escolher os traços do rosto, cabelo, expressões, movimentos, roupas e acessórios. Os avatares construídos podem interagir em histórias particulares, no próprio celular ou em ambientes virtuais com outros jogadores.

As classes apoiaram a proposta e decidimos que o 'trabalho final' seria apresentado com a animação neste game, que observamos possuir interface gráfica atrativa e de fácil utilização pelos estudantes. Apesar de estar disponível apenas em inglês, os alunos afirmaram não encontrar 
grande dificuldade para operações básicas. Percebemos o interesse dos discentes em explorar possibilidades de construção de personagens e histórias.

No decorrer das aulas, em rodas de conversa, apresentariam os resultados parciais escritos e desenhados em cartolinas.

Após coleta e análise dos dados das classes, revisão do conteúdo curricular, apresentação da proposta de trabalho e retorno dos alunos, iniciamos o plano de ensino de construção das narrativas audiovisuais - prevista para seis tempos de aula - com a narração da fábula creditada a Fedro ${ }^{6}$, "O Cavalo e o Javali ". Tal narrativa fabulesca, assim como outras de sua categoria textual, ensina uma lição, uma moral, ao ouvinte/leitor, possuindo a sensibilidade de atravessar o tempo e o espaço e manter-se compreensível (PORTELLA, 1983).

Dois alunos da unidade escolar, que participaram do assentamento PDS Osvaldo de Oliveira, foram convidados a relatar seu dia a dia, suas experiências pessoais e familiares. No decorrer da roda de conversa foram abordadas suas experiências no assentamento, surgindo questões feitas pelos colegas sobre violência, acesso à tecnologia, existência de animais selvagens, formas de trabalho, produção agrícola, festas e comércio.

As fontes foram, então, apresentadas com uso do Datashow, computador e caixa de som e debatidas em sala de aula. Os espaços pesquisados em Macaé foram visitados de forma virtual pelo Google Earth. Houve indicação dos endereços eletrônicos para que os alunos pudessem acessar fora do espaço escolar, nos seis dias que separaram a terceira da quarta aula prevista do presente estudo.

Para alcançar os objetivos propostos, ocorreu a divisão da turma em três grupos. Definimos “Grupo 1: Roma século II a.C.”; “Grupo 2: Brasil década de 1980 e 1990” e “Grupo 3: Macaé década de 2010”. Cada qual, selecionou acontecimentos no livro didático e nas fontes documentais hospedadas no ciberespaço, previamente escolhidas. Os acontecimentos foram utilizados na construção de uma linha do tempo temática, - relacionados a lutas sociais pela terra

\footnotetext{
6 "L. Gaius Julius Phaedrus ou Phaeder foi um escravo de origem trácia que se tornou liberto pela família de Augusto, ao chegar a Roma. Escreveu cinco livros, totalizando aproximadamente cem composições publicadas na era de Tibério e Calígula. É provável que Fedro tenha escrito ainda um apêndice com trinta e duas fábulas. As suas composições constam de fábulas propriamente ditas, de algumas pequenas histórias acerca de alguns personagens como Esopo e Sócrates e de textos de defesa contra difamadores. As fábulas de Fedro são baseadas nas de Esopo conhecido escritor de fábulas gregas que viveu em meados do século VI a.C.” (SALEMA, 2012: p. 60).

${ }^{7}$ A versão da fábula operada em sala de aula foi a hospedada no blog Contos de Encantar, escolhida pela facilidade de acesso aos alunos na dinâmica da aula. Disponível em:

< http://contosencantar.blogspot.com/2009/02/o-cavalo-e-o-javali.htm>.Acessado em: 28 mar. 2020.
} 
e ocupação do território.

O tratamento das fontes, proposto como atividade aos estudantes, tem início com a seleção de acontecimentos para formação de uma linha do tempo temática, sendo necessária a mobilização do conceito (CUESTA, 2015) de reforma agrária ${ }^{8}$ para identificar os eventos e ações humanas relacionadas à construção da narrativa.

O trabalho parcial desenvolvido, das linhas do tempo, foi apresentado em rodas de conversa com uso de cartolina, desenhos e celulares e discutido com outros estudantes. Nesta etapa, os alunos buscaram semelhanças e diferenças nas relações, lutas e disputas do território na Antiguidade Romana e no Brasil no Tempo Presente. Formularam analogias, tendo por base as relações humanas na ocupação do território, nos processos históricos apresentados.

Por fim, os discentes iniciaram a construção de uma narrativa escrita com diálogos e situações plausíveis de acordo com suas linhas do tempo, acontecimentos e personagens pesquisados, que veio a ser o roteiro utilizado na produção do audiovisual. Propusemos aos alunos que ao construírem suas narrativas ficcionais, pensassem as características da completude, totalidade e extensão apropriada (RICOEUR, 2010a). Ademais, os estudantes escrevem para apresentação aos colegas de classe e avaliação do professor. Em exposições orais do trabalho que promovem trocas entre os grupos, entre os diferentes processos históricos abordados na pesquisa.

\section{Resultados e discussão}

Foram construídas cinco narrativas audiovisuais com uso da imaginação no game Gacha Life (Tabela 3). As disputas pela ocupação do território, - e as desigualdades perceptíveis em Macaé no tempo presente -, foram operadas em sala de aula como temas geradores (FREIRE, 1987) para compreensão da experiência histórica romana. A luta pela terra foi lida em espaços e culturas diferentes.

\footnotetext{
${ }^{8}$ Segundo o dicionário de verbetes CPDOC (GUIMARÃES; MEDEIROS, [S.d.]) o termo 'Reforma Agrária' é cunhado no século XX, por vezes, operado para se referir as leis agrárias que de alguma forma intencionam modificar ou regular a estrutura agrária, em relação à produção e distribuição do território. Este objetivo está relacionado ao acúmulo de conceitos para leitura da própria realidade no presente (PEREIRA; SEFFNER, 2008).
} 
Tabela 3: Produção de vídeos dos estudantes hospedados no Youtube.

\begin{tabular}{|c|c|c|c|}
\hline Turma & Grupo & Tema & Link \\
\hline F6203 & 1 & $\begin{array}{c}\text { Roma } \\
\text { século II a.C. }\end{array}$ & $\begin{array}{l}\text { <https://www.youtube.com/watch?v=G0MmA8-wTa4 } \\
\text { \&list=PL3ZMgsq3S8DtUogE-02Gx5TyPBKkoex6L }\end{array}$ \\
\hline F6203 & 2 & $\begin{array}{l}\text { Brasil } \\
1980-1990\end{array}$ & $\begin{array}{l}\text { <https://www.youtube.com/watch? }=91 \text { WPMxg } \\
\text { Qhg\& list=PL3ZMgsq3S8DtUogE-02Gx5TyPBKkoex6L\&index=2> > }\end{array}$ \\
\hline F6203 & 3 & $\begin{array}{l}\text { Macaé } \\
\text { 2010-2019 }\end{array}$ & Não concluído. \\
\hline F6204 & 1 & $\begin{array}{l}\text { Roma } \\
\text { século II a.C. }\end{array}$ & $\frac{<\text { https://www.youtube.com/watch?v=G4FWYCtYVQU\&list }=}{\text { PL3ZMgsq3S8DtUogE-02Gx5TyPBKkoex6L\&index=3> }}$ \\
\hline F6204 & 2 & $\begin{array}{c}\text { Brasil } \\
1980-1990\end{array}$ & $\begin{array}{l}\text { 〈https://www.youtube.com/watch?v=31bsl_8sKzs\&list }= \\
\text { PL3ZMgsq3S8DtUogE-02Gx5TyPBKkoex6L\&_index }=4>\end{array}$ \\
\hline F6204 & 3 & $\begin{array}{c}\text { Macaé } \\
2010-2019\end{array}$ & $\begin{array}{c}\text { <https://www.youtube.com/watch?v=aTSvda3eg } \\
\text { PY\&list=PL3ZMgsq3S8DtUogE-02Gx5TyPBKkoex6L\&index=5> }\end{array}$ \\
\hline
\end{tabular}

Fonte: $\mathrm{O}$ autor, 2020.

Ao abordar as lutas sociais pela terra na experiência histórica romana (ALFÖLDY, 1989) no Brasil na década de 1980 e em Macaé na década de 2010, as linhas do tempo e narrativas que contemplaram as características da totalidade, completude e extensão apropriada indicaram o desenvolvimento da competência de tornar histórico o presente e mobilizar o conceito de reforma agrária em diferentes temporalidades.

Consideramos que a seleção de vídeos hospedados no YouTube e sites em endereços eletrônicos da internet, utilizadas como fontes documentais na elaboração do trabalho pelos alunos, promoveu a aula de História como um espaço intermediador entre a cultura letrada e a audiovisual, articulando diferentes formas de ler (FERNANDES, 2019).

Após a contação da fábula "O cavalo e o Javali", a opressão exercida por um dos personagens, foi reconhecida pelos estudantes como parte do presente no Brasil e do passado na República Romana. A 'moral da história' (PORTELLA, 1983) foi tornada reconhecível quando os alunos incorporaram suas próprias histórias às situações narradas (CUESTA, 2015). Discutimos acerca da recusa de diálogo dos personagens, sobre a forma de uso comum do território e abrimos a discussão sobre o conceito de reforma agrária.

No decorrer da roda de conversa com os estudantes que participaram do PDS Osvaldo de Oliveira percebemos o interesse dos alunos da classe no modo de vida, inicialmente como “outro", causador de certos receios e medos. Porém, no decorrer da aula, observamos haver a percepção de proximidades e desconstrução de ideias preconcebidas a respeito de violência e trabalho infantil.

Na etapa de construção da linha do tempo sob o tema da ocupação do território, os 
estudantes desenvolveram argumentos que mobilizaram a relação entre acontecimentos e continuidades, além de operar o conceito contemporâneo de reforma agrária em outra temporalidade - com suas semelhanças, diferenças e analogias (RICOEUR, 2010b). Enquanto os estudantes não haviam se apropriado do conceito da reforma agrária, ao selecionar os eventos para formular as narrativas, apresentaram sequências de episódios aleatórios que atravessavam diversos temas. Apesar de estarem na ordem cronológica correta, não havia noção de completude e totalidade, impossibilitando a configuração narrativa proposta pela atividade, que teve por objetivo operar o conceito histórico no agir humano. Portanto, os discentes ao completarem a atividade da linha do tempo temática haviam se apropriado do conceito de reforma agrária e o operado em diferentes processos históricos.

Ao pensarmos o processo de construção dos vídeos no aplicativo Gacha Life, a partir de nossa experiência pessoal de infância, o processo de criação é semelhante a certa atividade lúdica comum em nossa vivência de estudantes na Educação Básica: desenhar uma pessoa ou objeto na "orelha" do caderno (canto de cima ou de baixo) em várias folhas seguidas, com pequenas diferenças de posicionamento entre duas páginas em sequência. Ao passar rápido os papéis, havia a impressão que o objeto ou pessoa desenhada se movimentava. A estrutura da criação do vídeo é semelhante, porém, com o uso de tecnologia digital. A liberdade de experimentação criativa (LUCCHESI; MAYNARD, 2019) que o aplicativo oferece abre possibilidade de uso não só no ensino da experiência histórica romana como também em outros conteúdos, com potencial de serem exploradas pelos olhares curiosos dos discentes e a prática do professor. A cada conteúdo uma nova história, novos personagens e cenários podem ser construídos. Mostrou-se uma ferramenta de ensino na qual a imaginação e criatividade tiveram centralidade na mediação entre a cultura escrita e visual no espaço da sala de aula (FERNANDES, 2019).

Um resultado interessante foi a constante troca entre os grupos e mesmo entre diferentes classes. Durante o processo de edição do avatar de cada personagem, todos os alunos da equipe participavam sugerindo mudanças, dialogando sobre as interações e ações em relação ao contexto histórico e eventos selecionados em suas linhas do tempo. Exceto um grupo, que apresentou maior dificuldade em trabalhar de forma cooperativa e teve o resultado de não concluir a atividade na data proposta, apesar de já conhecerem o aplicativo e terem aparelhos celulares. Este pode ser um indicativo da relevância da promoção de métodos que incluam a cooperação entre os estudantes. 
Portanto, temos considerado que este aplicativo possui um grande potencial no ensino de História. Faz parte de uma diversidade de possibilidades de ferramentas gratuitas que a internet possibilita e podem ser utilizadas em sala de aula (LUCCHESI; MAYNARD, 2019).

Os alunos faziam muitas perguntas no decorrer de todo o processo de ensino, fenômeno que nos gerou a percepção de estarem motivados (SEFFNER, 2018). Realizamos um movimento de aproximação ao contexto histórico e social dos jovens - cujas empatias cognitivas e expressivas estão cada vez mais integradas a tecnologias digitais, que perpassam de modo significativo as ações criativas dos estudantes (FERNANDES, 2019).

Por utilizarem a imaginação e referências a suas vivências, os discentes incorporaram às narrativas questões de seus cotidianos. Discutiram em sala de aula suas vivências, operando os conceitos e habilidades históricas desenvolvidas nas atividades. Nas rodas de conversa, identificaram relações entre a cidade e o campo na oferta de alimentos, preços, emprego e qualidade de vida. Com a construção de analogias por parte dos alunos, percebemos a apropriação do conteúdo - a experiência histórica - numa narrativa imaginária plausível em espaço-tempo diverso e no agir de personagens do tempo presente.

Visitaram o passado com suas referências pessoais e ao retornar trouxeram as lutas sociais e disputas na ocupação do território na antiguidade romana, para questionar o presente. Questões como gravidez na adolescência, liberdade, pobreza, migração e desemprego aparecem nas narrativas construídas pelos alunos. Estas, na individualidade dos personagens, dialogaram com as disputas pelo território, inserindo os sujeitos imaginados em um processo coletivo.

Portanto, desde o processo de escolha de acontecimentos para uma linha do tempo, construção de personagens e da intriga, até a conclusão das narrativas com uso da imaginação, os sentidos que os alunos atribuíram ao passado, ante suas vivências no presente, são evidenciados.

Por que ensinar História na educação básica? Longe de apresentarmos uma resposta, buscamos provocar mais reflexões acerca dos sentidos que tal questionamento fazem emergir.

\section{Referências}

ALBUQUERQUE JR., Durval Muniz. Regimes de Historicidade: como se alimentar de narrativas temporais através do Ensino de História. In: GABRIEL, Carmem T.; MONTEIRO, Ana M.; MARTINS, Marcus L. B. (Org.). Narrativas do Rio de Janeiro nas Aulas de História. Rio de Janeiro: Mauad X, 2016.

ALCÂNTARA. Fernanda. Sob ameaça de despejo, famílias assentadas em Macaé (RJ) resistem e 
inauguram casa de farinha. Coletivo de Comunicação do MST RJ, 20 set. 2019. Disponível em: <https://mst.org.br/2019/09/20/sob-ameaca-de-despejo-familias-assentadas-em-macae-rjresistem-e-inauguram-casa-de-farinha/>. Acesso em: 08 mar. 2020.

ALFÖLDY, Géza. A Crise da República e a Sociedade Romana. Os conflitos na sociedade romana nos últimos tempos da república. In: A História Social de Roma. Lisboa: Presença, 1989.

BENITES, Marcello Riella. Sem-terra pedem para ficar provisoriamente em terra ocupada. Câmara Municipal de Macaé, Macaé, 26 jun. 2018. Disponível em: <http://www.cmmacae.rj.gov.br/sem-terra-pedem-para-ficar-provisoriamente-em-terraocupada/>. Acessado em: 28 mar. 2020.

BENJAMIN, Walter. O Narrador. In: Magia e Técnica, Arte e Política - ensaios sobre literatura e história da cultura. São Paulo: Brasiliense, 2012. Edição Kindle.

Experiência e Pobreza (1933). In: Magia e Técnica, Arte e Política - ensaios sobre literatura e história da cultura. São Paulo: Brasiliense, 2012. Edição Kindle.

BITTENCOURT, Circe Maria Fernandes. Identidades e ensino da história no Brasil. In: CARRETEIRO, Mario et al. (Org.) Ensino da história e memória coletiva. Porto Alegre: Artmed, 2007.

BOCAYUVA, I. Parmênides e Heráclito: diferença e sintonia. Kriterion: Revista de Filosofia, v. 51, n. 122, p. 399-412, dez. 2010.

BRASIL. Área territorial brasileira. Rio de Janeiro. Rio de Janeiro: IBGE, 2020a.

BRASIL. Cadastro Central de Empresas 2018. Rio de Janeiro: IBGE, 2020b.

BRASIL. Censo Agropecuário 2017 - Resultados definitivos. Rio de Janeiro: IBGE, 2019a.

BRASIL. Instituto Nacional De Estudos E Pesquisas Educacionais Anísio Teixeira. Censo da Educação Básica: Sinopse Estatística da Educação Básica 2018. Brasília: INEP, 2019b. Disponível em: 〈http://portal.inep.gov.br/sinopses-estatisticas-da-educacao-basica>. Acessado em: 23 mar. 2020.

BRASIL. Censo Demográfico 2010. Rio de Janeiro: IBGE, 2010a.

BRASIL. Decreto, de 1 de setembro de 2010. Declara de interesse social, para fins de reforma agrária, o imóvel rural denominado "Fazenda Bom Jardim", situado no Município de Macaé, Estado do Rio de Janeiro, e dá outras providências. Diário Oficial [da] República Federativa do Brasil, Poder Executivo, Brasília, DF, 2 set. 2010b. Seção 1, p. 41.

BRASIL. Ministério Público Federal. Turminha do MPF. Brasília, DF. Disponível em: $<$ http://www.turminha.mpf.mp.br/proteja-a-natureza/terra/turminha-aprende-sobre-reformaagraria-e-assentamento $>$. Acessado em: 07 fev. 2019. 
BRINCO, Naicon de Souza; CABRAL, Maria Aparecida da Silva. Ensino de História, aprendizagem significativa e a atuação do professor: desafios do tempo presente. Revista História Hoje, v. 9, n. 18, p. 55-76, 23 dez. 2020.

CANDAU, Vera. Memória (s), Diálogos e Buscas: Aprendendo e Ensinando Didática. In: , Vera (Org.). Didática Questões Contemporâneas. Rio de Janeiro: Forma e Ação, 2009.

CASTRO, Flora. No RJ, MST faz acordo com Prefeitura para construção de escola agroecológica em Macaé. Brasil de Fato, Rio de Janeiro, 18 mar. 2019. Disponível em: <https://www.brasildefatorj.com.br/2019/03/18/no-rio-mst-faz-acordo-com-prefeitura-paraconstrucao-de-escola-agroecologica>. Acessado em: 23 mar. 2020.

CUESTA, Virginia. Enseñanza de la História y enfoque narrativo. Revista História Hoje, v. 4, n. 8, p. 152-173. 2015.

FERNANDES, Adriana Hoffmann. Narrativa de crianças na sociedade da imagem. Curitiba: Appris, 2019.

FERREIRA, Rodrigo de Almeida. Qual a relação entre a história púbica e o ensino de História? In: MAUAD, Ana Maria; SANTHIAGO Ricardo; BORGES, Viviane Trindade (Org.). Que história pública queremos? São Paulo: Letra e Voz, 2018.

FIOCRUZ E FASE. RJ - A Luta de trabalhadores Rurais Sem Terra pelo assentamento Osvaldo de Oliveira. Mapa de conflitos envolvendo injustiça ambiental e saúde no Brasil. Disponível em: $\langle$ http://mapadeconflitos.ensp.fiocruz.br/?conflito=rj-a-luta-de-trabalhadores-rurais-sem-terrapelo-assentamento-osvaldo-de-oliveira>. Acessado em: 31 mar. 2020.

FREIRE, Paulo. Pedagogia do Oprimido. $17^{\circ}$ ed. Rio de Janeiro: Paz e Terra, 1987.

GUIMARÃES, Alberto Passos; MEDEIROS, Leonilde Servolo. Reforma Agrária. In: Dicionário Histórico-Biográfico Cpdoc-Fgv. Disponível em: <https://www.fgv.br/cpdoc/

acervo/dicionarios/verbete-tematico/reforma-agraria-5>. Acessado em: 07 mar. 2020.

HARTOG. Regimes de historicidade: presentismo e experiências do tempo. Belo Horizonte: Autêntica, 2013.

KALLÁS, Ana Lima. Usos públicos da história: origens do debate e desdobramentos no ensino de história. Revista História Hoje, v. 6, n. 12, p. 130-157, 2017.

KOSELLECK, Reinhart. Futuro Passado. Rio de Janeiro: PUC Rio/Contratempo, 2006.

LEAL, Giuliana Franco; COSTA, Rafael Nogueira. Sentidos da moradia e do bairro: estudo de caso de uma comunidade face à possibilidade de remoção. Boletim do Observatório Ambiental Alberto Ribeiro Lamego, v. 6, p. 43, 2012. Disponível em: < https://essentiaeditora.iff.edu.br/index.php/boletim/article/view/2177-4560.20120003/1530 >. Acessado em: 01 jun. 2020. 
LUCCHESI, Anita; MAYNARD, Dilton C. S.. Novas Tecnologias. In: FERREIRA, Marieta de Moraes Ferreira; OLIVEIRA, Margarida Dias de (coord.). Dicionário de Ensino de História. 1. ed. Rio de Janeiro: FGV, 2019. p. 179-184.

MACAÉ, Caderno de Orientações Curriculares. História. Macaé: Secretaria Municipal de Educação, 2012. Disponível em: 〈http://ntmmacae.com/ideb/arquivos/COC6ao9final.pdf >. Acessado em: 30 mar. 2020.

Revisão do Plano Diretor: Diagnóstico Geral do Município. Prefeitura Municipal de Macaé. Macaé: 2014. Disponível em: <http://www.macae.rj.gov.br/midia/conteudo/arquivos/

1429918917.pdf>. Acessado em: 30 mar. 2020.

MATTOS, Ilmar R. Mas não somente assim; leitores, autores, aulas como texto e o ensinoaprendizagem de História. Revista Tempo. Departamento de História da UFF. Rio de Janeiro, v. 11, n. 21, p. 5-16, jul. 2006.

MEMORIAL da Democracia. MST Realiza Primeiro Congresso Nacional. Disponível em: $<$ http://memorialdademocracia.com.br/card/mst-realiza-primeiro-congresso-nacional>.

Acessado em: 07 jun. 2019.

MESQUITA, Clívia. Famílias sem-terra compartilham saberes em Fórum de Agroecologia, em Macaé (RJ). Brasil de Fato, Rio de Janeiro, 27 abr. 2019. Disponível em: <https://www.brasildefatorj.com.br/2019/04/27/familias-sem-terra-compartilham-saberes-emforum-de-agroecologia-em-macae-ri >. Acessado em: 23 fev. 2020.

MONTEIRO, Jéssica Oliveira. Que a universidade se pinte de povo. Serviço Social $\mathbb{E}$ Sociedade, n. 129, p. 265-284, maio/ago. 2017.

MONTEIRO, Maria Isabel. Ministério aprova terreno para construção de matadouro. Prefeitura Municipal de Macaé. 13 abr. 2005. Disponível em: <http://www.macae.rj.gov.br/noticias/leitura/noticia/ministerio-aprova-terreno-paraconstrucao-de-matadouro $>$. Acessado em: 23 mar. 2020.

MST. Nossa História. Disponível em: 〈http://www.mst.org.br/nossa-historia/84-86>. Acessado em: 08 mar. 2019.

OlIVEIRA, Dayse Maria da Silva Caciano de. O Projeto de Desenvolvimento Sustentável (Pds) e a Construção de Novos Modelos de Assentamento Rural: O Caso do Assentamento Osvaldo de Oliveira do MST em Macaé-RJ. 2018. 194 f. Dissertação (Mestrado em Serviço Social e Desenvolvimento Regional) - Universidade Federal Fluminense, Niterói, 2018.

PELLEGRINI, Marcos Cesar; DIAS, Adriana Machado; GRINBERG, Keila. Vontade De Saber História. 3. ed. São Paulo: FTD, 2015. p. 223-242.

PEREIRA, Nilton Mullet; SEFFNER, Fernando. O que pode o ensino de história? Sobre o uso de fontes na sala de aula. Anos 90. Porto Alegre, v. 15, n. 28, dez. 2008. 
PITASSE, Mariane. Mais de 60 famílias assentadas estão sob ameaça de despejo em Macaé (RJ). Coletivo de Comunicação do MST RJ, 5 set. 2019. Disponível em: <https://mst.org.br/2019/09/05/mais-de-60-familias-assentadas-estao-sob-ameaca-de-despejoem-macae-rj/>. Acessado em: 08 mar. 2020.

PORTELLA, Oswaldo O. A fábula. Revista Letras, v. 32, 1983.

RAMOS, Fábio Pestana. O problema dos sem-terra não é de hoje: a reforma agrária na Roma Antiga. Blog Para Entender História. 7 set. 2010. Disponível em:

$<$ http://fabiopestanaramos.blogspot.com/search/label/Reforma\%20Agr\%C3\%A1ria $>$. Acesso em: 08 mar. 2020.

REDAÇÃO. Implantação de Escola Agroecológica na Serra recebe apoio na Câmara. Jornal O Debate On, Macaé, 27 jun. 2018. Caderno Notícia Política. Disponível em: <https://www.odebateon.com.br/implantacao-de-escola-agroecologica-na-serra-recebe-apoio-nacamara/>. Acessado em: 08 mar. 2020.

RICOEUR, Paul. Tempo e narrativa: A intriga e a narrativa histórica. 1. ed. São Paulo: WMF Martins Fontes, 2010a. v. 1.

. Tempo e narrativa: O tempo narrado. 1. ed. São Paulo: WMF Martins Fontes, 2010b. v. 3. . Ética e moral. Covilhã: LusoSofia, 2011.

SALEMA, Vivian de Azevedo Garcia. O discurso das fábulas de Fedro. Principia, Rio de Janeiro, n. 24, 2012.

SANTOS, Edméa; WEBER, Aline. Diários online, cibercultura e pesquisa-formação multirreferencial. In: SANTOS, Edméa (Org.). Diário online: dispositivo Multirereferencial de pesquisa formação na cibercultura. Whitebooks: Santo Tirso, Portugal, 2014.

SEFFNER, Fernando. Aprender e ensinar história: como jogar com isso? In: GIACOMONI, Marcello Paniz; PEREIRA, Nilton Mullet (Orgs.). Jogos e ensino de história. Porto Alegre: Editora da UFRGS, 2018. p. 19-34.

SEM TERRINHA em Movimento. Direção: Brigada de Audiovisual do MST. Disponível no link: $<$ https://www.youtube.com/watch?v=CQF6a838wD0>. Acessado em: 08 mar. 2020.

TARDIF, Maurice. Os Professores diante do saber: esboço de uma problemática do saber docente. In: . Saberes docentes e formação profissional. Rio de Janeiro: Vozes, 2012.

UNIDADE Pedagógica De Agroecologia Acampamento Edson Nogueira (RJ). Direção: Brigada Audiovisual Eduardo Coutinho (MST). Rio de Janeiro: Coletivo de Comunicação MST - RJ, 2019. Som e cor (2 min. 37 seg.). Disponível em:

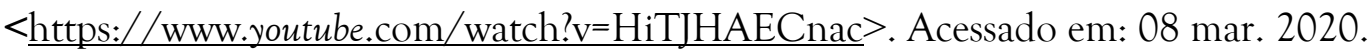


VARGAS, Laís. Famílias Sem Terra são despejadas de terras improdutivas em Rio das Ostras. Prensa de Babel, Rio das Ostras, 2 maio 2018. Disponível em: <https://prensadebabel.com.br/index.php/2018/05/02/familias-sem-terra-sao-despejadas-deterras-improdutivas-em-rio-das-ostras/>. Acessado em: 23 mar. 2020.

VERGARA, Pablo. Famílias Sem Terra comemoram a aprovação de Unidade Pedagógica no Rio de Janeiro. MST, 21 fev. 2019. Disponível em: <https://mst.org.br/2019/02/21/familias-semterra-comemoram-a-aprovacao-de-unidade-pedagogica-no-rio-de-janeiro/>. Acessado em: 23 fev. 2020 .

VIDA Maria. Direção: Márcio Ramos. Ceará: Synapse Produções Ltda, 2006. Disponível: < https://www.youtube.com/watch?v=yFpoG htum4 >. Acessado em: 07 mar. 2020.

VIGOTSKI, Lev Semenovich. Pensamento e Linguagem. trad. Jefferson Luiz Camargo. 4a Edição. São Paulo: Martins Fontes, 2008.

\section{Sobre o autor:}

Naicon de Souza Brinco: Professor de História da Educação Básica na Prefeitura Municipal de Macaé. Mestre em Ensino de História (Mestrado Profissional em Ensino de História - UERJ, 2020).

Artigo recebido para publicação em: 12 de setembro de 2021.

Artigo aprovado para publicação em: 02 de dezembro de 2021.

\section{Como citar:}

BRINCO, Naicon de Souza. Ensino de História na educação básica: a experiência histórica romana, e o tempo presente, na sala de aula. Revista Transversos. Dossiê: O futuro do passado: Desafios para o Ensino da História nas escolas numa perspectiva global. Rio de Janeiro, nº 23 , 2021. 230-251. Dp. Disponível em: <https://www.epublicacoes.uerj.br/index.php/transversos/article/view/62326>. ISSN 2179-7528. DOI: $10.12957 /$ transversos.2021.62326

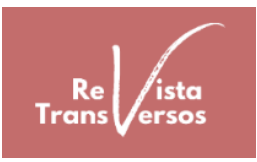

